\title{
Is hydroxychloroquine effective in treating primary Sjogren's syndrome: a systematic review and meta-analysis
}

\author{
Shi-Qin Wang, Li-Wei Zhang, Pan Wei and Hong Hua*
}

\begin{abstract}
Background: To systematically review and assess the efficacy and safety of hydroxychloroquine (HCQ) for treating primary Sjogren's syndrome (pSS).

Methods: Five electronic databases (Pubmed, EMBASE, Web of science, Ovid, Cochrane Library) were searched for randomized controlled trials and retrospective or prospective studies published in English that reported the effect of HCQ on pSS. The subjective symptoms (sicca symptoms, fatigue and pain) and the objective indexes (erythrocyte sedimentation rate and Schirmer test) were assessed as main outcome measures. A meta-analysis and descriptive study on the efficacy and safety of HCQ were conducted. The estimate of the effect of HCQ treatment was expressed as a proportion together with 95\% confidence interval, and plotted on a forest plot.

Results: Four trials with totals of 215 SS patients, including two randomized controlled trials, one double blind crossover trial and one retrospective open-label study, were analyzed in this review. For dry mouth and dry eyes, the effectiveness of HCQ treatment was essentially the same as placebo treatment. For fatigue, the effectiveness of HCQ was lower than placebo. The efficacy of HCQ in treating pain associated with pSS was superior to that of the placebo. There was no significant difference between HCQ-treated groups and controls in terms of Schirmer test results, but HCQ could reduce the erythrocyte sedimentation rate compare with placebo. A descriptive safety assessment showed that gastrointestinal adverse effects were the most common adverse effects associated with HCQ.

Conclusions: This systematic review showed that there is no significant difference between HCQ and placebo in the treatment of dry mouth and dry eye in pSS. Well-designed, randomized, controlled trials are needed to provide higher-quality evidence to confirm our findings, and future studies should focus on some other index or extraglandular measures, such as cutaneous manifestations, to further explore the therapeutic effect of HCQ in pSS.
\end{abstract}

Keywords: Sjogren's syndrome, Hydroxychloroquine, Systematic review, Meta-analysis

\section{Background}

Sjögren's syndrome (SS) is a complex chronic autoimmune disease characterized by a wide spectrum of clinical manifestations. Lymphocytic infiltration and destruction of exocrine glands (mainly the salivary and lacrimal glands) is the histological hallmark of SS, leading to reduced lacrimal and salivary flow [1-3]. Dry eyes

\footnotetext{
*Correspondence: honghua1968@aliyun.com

Department of Oral Medicine, Peking University School and Hospital of Stomatology \& National Engineering Laboratory for Digital and Material Technology of Stomatology, 22 South Zhongguancun Avenue, Haidian District, Beijing 100081, China
}

and dry mouth together with fatigue are among the most common complaints [4]. Extraglandular manifestations affect various organs including the skin, heart, lungs, kidney, gastrointestinal and endocrine system, as well as the central and peripheral nervous system [5-7]. SS with the presence of disorders mentioned above may occur alone without additional connective tissue diseases, as the primary SS (pSS), or may be associated to other autoimmune diseases, including systemic lupus erythematosus (SLE), rheumatoid arthritis (RA), and scleroderma, as secondary Sjogren's syndrome (sSS) [8]. SS 
has an estimated prevalence of $0.5-4.8 \%$ [8-10], affecting approximately 1.5 to 4 million people in the USA based on a total population of 300 million [11]. The current epidemiological data indicate that the annual incidence rate of pSS is 6.92 people per 100,000 (95\% confidence interval $[\mathrm{CI}]: 4.98$ to 8.86$)$. The prevalence rate is 60.82 people per 100,000 (95\% CI: 43.69 to 77.94 ) [12]. According to previous report, the standardized mortality ratio ranges from 1.02 to 4.66 , implying the impossible impact of pSS on patients' survival [13]. In most research, the increased mortality in pSS is mainly attributed to lymphoma [13]. The pooled risk ratio was 13.76 (95\% CI 8.53 to 18.99$)$ for nonHodgkin lymphoma in pSS patients compared with the general populations [14].

The etiology and pathogenesis of this disease have not yet been elucidated, and it has been suggested that viral, hormonal, genetic, environmental, and neurophysiological factors might contribute to the initiation and progression of the disease [15-17]. Overexpression of proinflammatory cytokines, such as interleukin-1, and interleukin-17, and lower expression of anti-inflammatory cytokine, such as interleukin-4 is an important manifestation of immune disorder in SS [18, 19]. Recent advances in the understanding of its pathogenesis have uncovered some pathways that have potential as therapeutic targets. Activated B lymphocytes are a hallmark of the disease, which is also characterized by the presence of rheumatoid factor, hypergammaglobulinemia, and autoantibody to Ro/ Sjogren's-syndrome-related antigen A and La/Sjogren'ssyndrome-related antigen B [20]. In contrast, B cell depletion could result in normalization of the elevated levels of circulating follicular Th cells, which might be associated with lower systemic disease activity over time [21].

Among all chronic autoimmune rheumatic disorders, SS remains one of the most difficult to manage. At present, no curative agent exists [22]. Therapeutic goals remain symptom palliation, systemic damage prevention and life quality improvement. Suppression of an excessive abnormal immune response is key to critical patient care. The treatment method focuses on the disease process $[23,24]$. When severe visceral damage is present, glucocorticoids or immunosuppressive therapy can be applied [23, 25]. Commonly applied immunosuppressive agents include tumor necrosis factor inhibitors, rituximab, hydroxychloroquine (HCQ), methotrexate and cyclophosphamide [22, 26].

HCQ is one of the first drugs applied in the treatment of rheumatism and plays an important role in alleviating fever. It controls arthritis and eliminates rash through complex mechanisms, such as anti-inflammation, immunosuppression, and immunomodulation $[27,28]$. The efficacy of HCQ in the treatment of SLE [29] and RA [30] is already widely recognized, but its efficacy in the treatment of pSS is in dispute. Some studies have shown that it is effective in the treatment of pSS [31-33]. It is commonly used to treat fatigue, arthralgia, and myalgia [22, 34-36]. However, there are also studies that have come to the conclusion that it is not an effective treatment for pSS [37, 38]. Two recently published randomized controlled trials (RCTs) suggest that HCQ has no significant effect as compared with placebo [39, 40]. In the latest Sjogren's Syndrome Foundation Clinical Practice Guidelines, HCQ is recommended as a first-line therapy for inflammatory musculoskeletal pain associated with pSS, and a moderate medication strength is recommended [41]. In terms of the recommended treatment for fatigue in pSS patients, HCQ may be considered for selective treatment of this symptom, and it is recommended to be administered at a weak strength. Currently, a systematic evaluation of the efficacy of HCQ in the treatment of pSS has not been conducted. This study is intended to provide a systematic evaluation of the efficacy and safety of HCQ in the treatment of pSS.

\section{Methods}

This review was performed following the preferred reporting items for systematic reviews and meta-analyses (PRISMA) guidelines [42].

\section{Inclusion criteria}

RCTs, retrospective studies, and prospective studies that used HCQ for pSS treatment were included in this review. There were no restrictions on patient age, sex, or race. The outcome measures included assessment for the remission of subjective symptoms such as dry mouth, dry eyes, pain, fatigue and the objective indexes, which contained erythrocyte sedimentation rate (ESR), Schirmer test and salivary flow rate. The diagnosis of SS was based on clinical assessment and laboratory examination, with or without histological evaluation.

\section{Exclusion criteria}

For subjective symptoms, including sicca manifestations, pain and fatigue, dichotomous variables were used to evaluate the efficacy of HCQ treatment. If effective rate of HCQ treatment for subjective symptoms was not provided or not available according to original data, the research would be excluded. The continuous variables were used to assess the efficacy of HCQ for objective indices, control group was essential to conduct metaanalysis. Research regarding to objective indices without control group would be excluded from the analysis. Studies with a sample size of less than five patients were not included. 


\section{Outcome evaluation}

Outcome evaluation was based on primary and secondary outcomes. Primary outcomes were defined as the remission of the subjective symptoms of pSS, such as dry mouth, dry eyes, pain and fatigue. The effective rate would be calculated. Secondary outcomes were defined as the difference value before and after treatment of objective indexes, including ESR, Schirmer test and salivary flow rate. The adverse effects of interventions were also assessed.

\section{Database search strategies}

All clinical trials in English that reported the effect on pSS of treatment with HCQ were selected in Pubmed, Excerpta Medica dataBASE (EMBASE), Web of science, Ovid and Cochrane Library. These databases were searched up to September 2016. The following combined terms were searched: "Hydroxychloroquine" OR "Oxychlorochin" OR "Oxychloroquine" OR "Hydroxychlorochin" OR "Plaquenil”) AND ("Sjogren's Syndrome” OR "Sjogrens Syndrome" OR "Sjogren Syndrome" OR "Sicca Syndrome"). Manual searches were also conducted as a supplement. The searches were conducted by two independent investigators (Shi-Qin Wang and LiWei Zhang).

\section{Data extraction and quality assessment}

The two authors (Shi-Qin Wang and Li-Wei Zhang) were independently responsible for scanning titles and abstracts, selecting studies, reading full reports, extracting data, and assessing the quality of studies; these steps were performed in duplicate by each of these authors. A third reviewer (Hong Hua or Pan Wei) was invited to make an assessment if the two review authors could not reach a consensus. All the relevant data from each study including author, year of publication, characteristics of patients, detailed interventions, outcomes, and adverse effects were extracted and summarized in table format.

The quality of the studies was assessed using the Downs and Black quality assessment tool that contains a list of 27 criteria for evaluation of the reporting, external validity, internal validity-bias, confounding (selection bias), and the power of assessed studies [43]. The level of evidence represented by each study was categorized based on the Oxford Centre for Evidence-Based Medicine Levels of Evidence (OCEBM. http://www.cebm.net/ index.aspx? $0=5653)$. The OCEBM classifies the evidence levels of the research into five grades, with levels ranging from level 1 to level 5 .

\section{Statistical analysis}

The efficacy of HCQ was evaluated using StatsDirect 2.8.0 software (Stats-Direct Ltd, Altrincham, UK, 2013). The estimate of the effect of an intervention was expressed as a proportion together with a 95\% confidence interval (CI), and plotted on a forest plot. The weighted mean difference was used for meta-analysis of continuous data. Cochran $\mathrm{Q}$ and $\mathrm{I}^{2}$ tests were performed to evaluate the heterogeneity of the studies. The random effect model was used when the test highlighted differences between studies, and the fixed-effect model was used when no significant differences were found [44]. When $P<0.05$ and $\mathrm{I}^{2}>0.25$, the effect size heterogeneity was considered statistically significant [45].

\section{Results}

\section{Identification of studies}

A total of 642 articles were obtained from five databases, 271 duplicates and 319 articles that did not meet the inclusion criteria were excluded. The remaining papers were analyzed, and from these, eight reviews, 27 conference summaries, three case reports, eight articles not in English and two articles with no pertinent full text were excluded. Finally, four studies [31, 37, 39, 40] were included in this review (Fig. 1).

\section{Characteristics of the studies}

The characteristics of the four studies are summarized in Additional file 1. A total of 215 SS patients were included in this review. One [31] of the four studies did not use a control group. The sample size ranged from 19 to 120 patients in each study. The treatment duration ranged from 12 weeks to 2 years.

\section{Quality of studies}

The median methodological quality score for all four studies, based on the Downs and Black criteria, was 28/ 32 (range 21 to 31). None of the included studies achieved a full score. In terms of the OCEBM Levels of Evidence, three studies [37, 39, 40] belonged to Level 2 and one study [31] belonged to Level 4 (Table 1).

\section{Effects of HCQ}

The data from the included studies for meta-analysis are summarized in Table 2 and Table 3, and the results of the meta-analysis are shown in Tables 4 and 5 . The pooled reduced proportions of subjective symptoms including dry mouth, dry eyes, pain and fatigue were analyzed (Table 4). For dry mouth, the efficacy of HCQ treatment (pooled proportion $=47.9 \% ; 95 \% \mathrm{CI}=38.2-57.8 \%$ ) was slightly higher than placebo treatment (pooled proportion $=42.6 \%$; $95 \% \mathrm{CI}=30.6-55.1 \%$ ), as depicted in Figs. 2 and 3. For dry eyes, the efficacy of HCQ treatment (pooled proportion $=50.6 \% ; 95 \% \mathrm{CI}=40.8-60.3 \%$ ) was higher than placebo (pooled proportion $=46.4 \%$; $95 \% \mathrm{CI}$ $=28.8-64.5 \%$ ), as shown in Table 4, and Figs. 4 and 5. The results show that the efficacy of HCQ treatment (pooled proportion $=48.9 \%$; $95 \% \mathrm{CI}=38.7-59.1 \%$ ) for SS pain was 


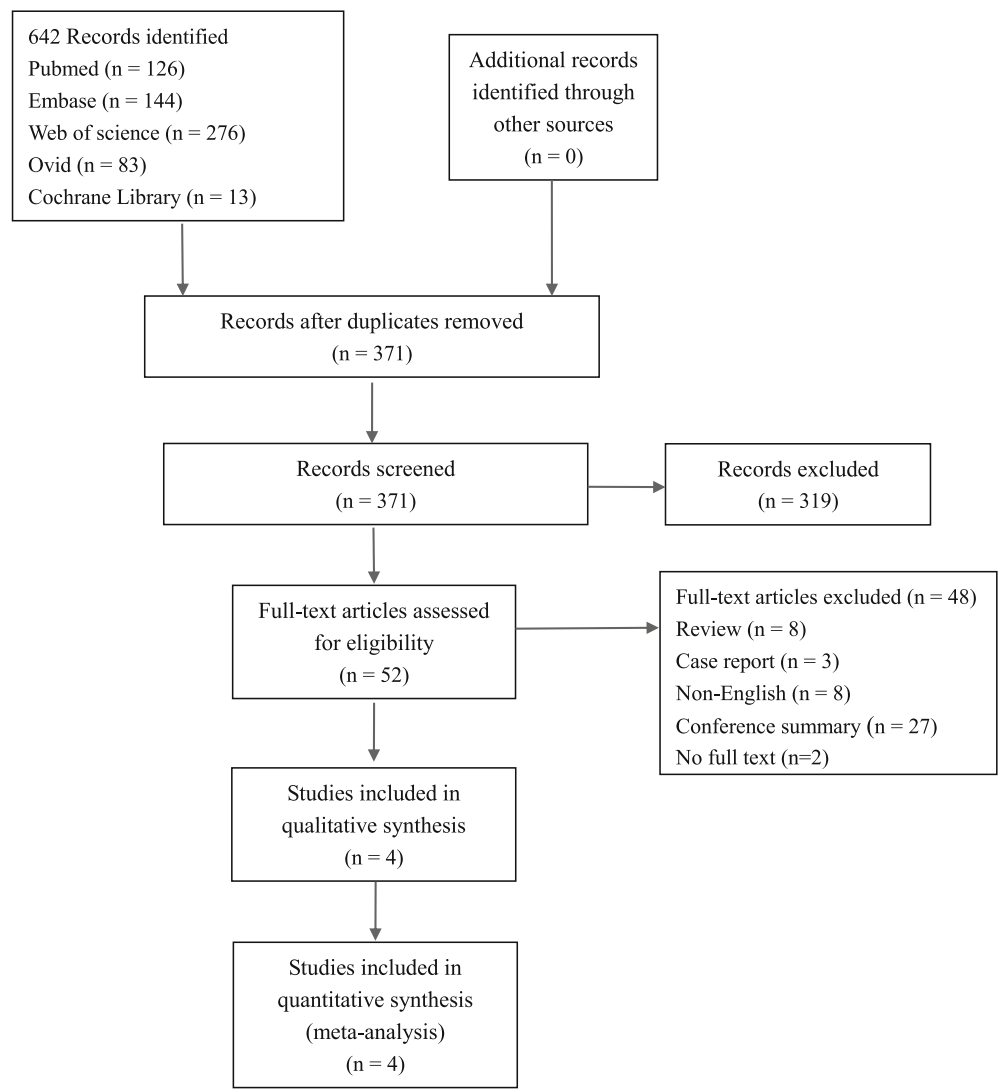

Fig. 1 Flowchart showing the selection of articles

higher than placebo treatment (pooled proportion = 35.8\%; 95\% CI $=23.5-49.0 \%$; Table 4 and Figs. 6 and 7). For fatigue, the efficacy of HCQ (pooled proportion = $35.9 \%$; $95 \% \mathrm{CI}=19.5-54.2 \%)$ was lower than that of the placebo (pooled proportion $=51.4 \%$; $95 \% \mathrm{CI}=7.7-93.8 \%$; Table 4 and Figs. 8 and 9). For the objective indexes, as salivary flow rate was only measured in one study which could not be used for meta-analysis, so only the pooled weighted mean difference of the ESR and Schirmer test were analyzed (Table 5), and it was found that HCQ treatment could reduce the ESR of SS patients $(Z=-2.19, \quad P<0.05$; Fig. 10$)$, however, there was no statistically significant difference in Schirmer test $(\mathrm{Z}=$ 0.04, $P=0.97$; Fig. 11 ).

\section{Safety assessment}

Among the four articles included in this review, three $[31,37,39]$ reported adverse effects or serious adverse events associated with HCQ treatment for pSS. Among the 116 patients in the HCQ group, there were nine adverse effects and two serious adverse events. One study [31] did not show the details of the adverse effects and only the number of adverse effects was reported. In the current systematic review, the most common adverse effects were gastrointestinal side effects, which occurred in five among the nine patients who had side effects after HCQ treatment. In the study by Kruize et al. [37], one patient demonstrated liver damage after receiving HCQ. In the study by Gottenberg et al. [39], there were two

Table 1 Quality assessment of included studies

\begin{tabular}{|c|c|c|c|c|c|c|c|c|c|c|}
\hline \multirow[t]{2}{*}{ Author } & \multirow[t]{2}{*}{ Year } & \multirow[t]{2}{*}{ Region } & \multirow[t]{2}{*}{ Study design } & \multicolumn{6}{|c|}{ Downs and Black quality score } & \multirow{2}{*}{$\begin{array}{l}\text { OCEBM level } \\
\text { of evidence }\end{array}$} \\
\hline & & & & $\begin{array}{l}\text { Reporting } \\
\text { (11) }\end{array}$ & $\begin{array}{l}\text { External validity } \\
\text { (3) }\end{array}$ & $\begin{array}{l}\text { Internal validity - } \\
\text { bias (7) }\end{array}$ & $\begin{array}{l}\text { Internal validity - } \\
\text { confounding (6) }\end{array}$ & $\begin{array}{l}\text { Power } \\
\text { (5) }\end{array}$ & $\begin{array}{l}\text { Total } \\
\text { (32) }\end{array}$ & \\
\hline Yoon C.H. et al. & 2016 & Korea & $\mathrm{RCT}$ & 9 & 3 & 6 & 6 & 5 & 29 & Level 2 \\
\hline $\begin{array}{l}\text { Gottenberg J.E. } \\
\text { et al. }\end{array}$ & 2014 & France & $\mathrm{RCT}$ & 10 & 3 & 7 & 6 & 5 & 31 & Level 2 \\
\hline Fox R.I. et al. & 1996 & USA & Retrospective & 10 & 0 & 3 & 3 & 5 & 21 & Level 4 \\
\hline Kruize A.A. et al. & 1993 & Netherlands & Cross-over & 10 & 2 & 7 & 5 & 3 & 27 & Level 2 \\
\hline
\end{tabular}


Table 2 Data of subjective symptoms and adverse effects or serious adverse events in the included studies

\begin{tabular}{|c|c|c|c|c|c|}
\hline Author & Year & Region & Total No. and No. of events & Hydroxychloroquine & Placebo \\
\hline \multirow[t]{11}{*}{ Gottenberg J.E. et al. } & \multirow[t]{11}{*}{2014} & \multirow[t]{11}{*}{ France } & Total patients & 56 & 64 \\
\hline & & & No. of dry mouth & 50 & 53 \\
\hline & & & No. of improved (\%) & $21(42.0)$ & $22(41.5)$ \\
\hline & & & No. of dry eyes & 50 & 53 \\
\hline & & & No. of improved (\%) & $21(42.0)$ & $22(41.5)$ \\
\hline & & & No. of pain & 46 & 47 \\
\hline & & & No. of improved (\%) & $25(54.3)$ & $17(36.2)$ \\
\hline & & & No. of fatigue & 48 & 50 \\
\hline & & & No. of improved (\%) & $11(22.9)$ & $14(28.0)$ \\
\hline & & & No. of adverse effects & - & - \\
\hline & & & No. of serious adverse events & 2 & 3 \\
\hline \multirow[t]{11}{*}{ Fox R.I. et al. } & \multirow[t]{11}{*}{1996} & \multirow[t]{11}{*}{ USA } & Total patients & 50 & - \\
\hline & & & No. of dry mouth & 40 & - \\
\hline & & & No. of improved (\%) & $23(57.5)$ & - \\
\hline & & & No. of dry eyes & 40 & - \\
\hline & & & No. of improved (\%) & $25(62.5)$ & - \\
\hline & & & No. of pain & 40 & - \\
\hline & & & No. of improved (\%) & $17(42.5)$ & - \\
\hline & & & No. of fatigue & 40 & - \\
\hline & & & No. of improved (\%) & $15(37.5)$ & - \\
\hline & & & No. of adverse effects & 8 & - \\
\hline & & & No. of serious adverse events & - & - \\
\hline \multirow[t]{11}{*}{ Kruize A.A. et al. } & \multirow[t]{11}{*}{1993} & \multirow[t]{11}{*}{ Netherlands } & Total patients & 10 & 9 \\
\hline & & & No. of dry mouth & 6 & 6 \\
\hline & & & No. of improved (\%) & $2(33.3)$ & $3(50.0)$ \\
\hline & & & No. of dry eyes & 7 & 6 \\
\hline & & & No. of improved (\%) & $3(42.9)$ & $4(66.7)$ \\
\hline & & & No. of pain & 2 & 4 \\
\hline & & & No. of improved (\%) & $1(50.0)$ & $1(25.0)$ \\
\hline & & & No. of fatigue & 6 & 6 \\
\hline & & & No. of improved (\%) & $4(66.7)$ & $5(83.3)$ \\
\hline & & & No. of adverse effects & 1 & 0 \\
\hline & & & No. of serious adverse events & - & - \\
\hline
\end{tabular}

Table 3 Data of erythrocyte sedimentation rate and Schirmer test results in the included studies

\begin{tabular}{|c|c|c|c|c|c|c|c|c|c|}
\hline \multirow[t]{2}{*}{ Author } & \multirow[t]{2}{*}{ Year } & \multirow[t]{2}{*}{ Region } & \multirow[t]{2}{*}{ Outcomes } & \multicolumn{3}{|c|}{ Hydroxychloroquine } & \multicolumn{3}{|c|}{ Placebo } \\
\hline & & & & $\mathrm{N}$ & Mean difference & sd & $\mathrm{N}$ & Mean difference & $\mathrm{sd}$ \\
\hline \multirow[t]{2}{*}{ Yoon C.H et al. } & 2016 & Korea & ESR & 11 & -3.64 & 19.30 & 15 & 1.73 & 11.75 \\
\hline & & & Schirmer test & 11 & -1.45 & 4.31 & 15 & -0.80 & 2.89 \\
\hline \multirow[t]{2}{*}{ Gottenberg J.E et al. } & 2014 & France & ESR & 44 & -4.0 & 22.3 & 48 & 3.7 & 15.5 \\
\hline & & & Schirmer test & 37 & 2.14 & 8.83 & 36 & 0.62 & 7.50 \\
\hline \multirow[t]{2}{*}{ Kruize A.A et al. } & 1993 & Netherlands & ESR & 8 & -10.3 & 17.1 & 6 & -0.9 & 25.5 \\
\hline & & & Schirmer test & 8 & -1.6 & 9.4 & 6 & 0.3 & 7.6 \\
\hline
\end{tabular}


Table 4 Results of the meta-analysis concerning subjective symptoms

\begin{tabular}{|c|c|c|}
\hline & Hydroxychloroquine & Placebo \\
\hline \multicolumn{3}{|l|}{ Total, dry mouth } \\
\hline No. of studies & 3 & 2 \\
\hline Total patients observed & 96 & 59 \\
\hline No. of improved & 48 & 25 \\
\hline $\begin{array}{l}\text { Pooled proportion, } \\
\%(95 \% \mathrm{Cl})\end{array}$ & 47.9 (38.2 to 57.8$)$ & 42.6 (30.6 to 55.1$)$ \\
\hline$I^{2}$ Inconsistency & 22.6 & - \\
\hline \multicolumn{3}{|l|}{ Total, dry eyes } \\
\hline No. of studies & 3 & 2 \\
\hline Total patients observed & 97 & 59 \\
\hline No. of improved & 49 & 26 \\
\hline $\begin{array}{l}\text { Pooled proportion, } \\
\%(95 \% \mathrm{Cl})\end{array}$ & 50.6 (40.8 to 60.3$)$ & 46.4 (28.8 to 64.5$)$ \\
\hline$I^{2}$ Inconsistency & 48.4 & - \\
\hline \multicolumn{3}{|l|}{ Total, pain } \\
\hline No. of studies & 3 & 2 \\
\hline Total patients observed & 88 & 51 \\
\hline No. of improved & 43 & 18 \\
\hline $\begin{array}{l}\text { Pooled proportion, } \\
\%(95 \% \mathrm{Cl})\end{array}$ & 48.9 (38.7 to 59.1) & 35.8 (23.5 to 49.0$)$ \\
\hline$I^{2}$ Inconsistency & 0 & - \\
\hline \multicolumn{3}{|l|}{ Total, fatigue } \\
\hline No. of studies & 3 & 2 \\
\hline Total patients observed & 94 & 56 \\
\hline No. of improved & 30 & 19 \\
\hline $\begin{array}{l}\text { Pooled proportion, } \\
\%(95 \% \mathrm{Cl})\end{array}$ & 35.9 (19.5 to 54.2$)$ & 51.4 (7.7 to 93.8) \\
\hline $\mathrm{I}^{2}$ Inconsistency & 63.4 & - \\
\hline
\end{tabular}

(urinary lithiasis, breast cancer) serious adverse events in the HCQ group and three (surgery for meningioma, lipothymia, Epstein-Barr virus (EBV) and cytomegalovirus (CMV) pneumonia) in the placebo group (Table 2).

\section{Discussion}

In this meta-analysis, four trials with totals of 215 SS patients were analyzed. The efficacy of HCQ in SS was not superior or even inferior to placebo regarding to the subjective symptoms, including dry mouth, dry eyes and fatigue. The effectiveness of $\mathrm{HCQ}$ in treating pain associated with pSS was higher than that of the placebo. And HCQ treatment could also reduce the ESR of pSS patients,however, when considering the treatment result of Schirmer test, no significant difference between HCQ and control groups was found. Gastrointestinal adverse effects were the most common adverse effects among patients treated with $\mathrm{HCQ}$.

HCQ was synthesized by Surrey and Hammer in 1950. It can control arthritis and eliminate rash through its anti-inflammatory, immunosuppressive, and immunomodulatory functions. For approximately 70 years, HCQ has been employed for the treatment of SLE and RA [28], and the efficacy of HCQ in the treatment of SLE [29] and RA [30] is widely recognized. The earliest study on the treatment of SS with HCQ was published in 1963 [46], and although there was a long history of research on the subject, the majority of studies were not conducted until the 1990s [47-49]. HCQ is widely used in clinical practice to treat SS [50], but its efficacy for this application is still controversial. Some studies [31, 33, 51, 52] indicate that HCQ is effective in the treatment of SS. In 1988, Fox et al. [51] observed that the total immunoglobulin G of SS patients significantly decreased in a HCQ treatment group. Another study conducted by Fox et al. in 1996 [31] reported that a sustained improvement of local symptoms (painful eyes, painful mouth) and an improvement in systemic manifestations (arthralgias and myalgias) in pSS patients were found after treatment with HCQ. In an open label study conducted by Tishler et al. indicated that HCQ could significantly reduce some salivary inflammatory markers in SS patients [32]. In 2011, Yavuz et al. [52] demonstrated that HCQ may alleviate the signs and symptoms of dry eyes in pSS and decrease tear fluid B-cell activator factor (BAFF) levels. In 2013, Mumcu et al. [33] showed that salivary and serum BAFF levels were lowered in patients with pSS when treated with $\mathrm{HCQ}$, and also that decreased disease activity and increased salivary flow could be achieved using HCQ treatment in pSS patients.

However, other studies [37-40] have demonstrated that HCQ treatment in SS is ineffective. In particular, two recent RCT studies have found that HCQ had a very limited effect on SS. In 2014, Gottenberg et al. [39] found that among patients with pSS, the use of HCQ did not improve symptoms compared with placebo during 24 weeks of treatment. In 2016, Chang et al. [40] showed that HCQ at $300 \mathrm{mg}$ daily for 12 weeks had no

Table 5 Results of the meta-analysis: erythrocyte sedimentation rate and Schirmer test

\begin{tabular}{|c|c|c|c|c|c|c|c|c|}
\hline \multirow[t]{2}{*}{ Test } & \multirow[t]{2}{*}{ Control } & \multirow{2}{*}{$\begin{array}{l}\text { Study } \\
\text { number }\end{array}$} & \multicolumn{3}{|c|}{ Patient number } & \multirow{2}{*}{$\begin{array}{l}\text { Pooled effect size } \\
\text { wmd }(95 \% \mathrm{Cl})\end{array}$} & \multirow[t]{2}{*}{$P$-value } & \multirow[t]{2}{*}{$\mathrm{I}^{2}(\%)$} \\
\hline & & & HCQ group & Control group & Total & & & \\
\hline ESR & Placebo & 3 & 63 & 69 & 132 & $-7.24(-13.72$ to -0.76$)$ & 0.03 & 0.0 \\
\hline Schirmer test & Placebo & 3 & 56 & 57 & 113 & $0.04(-2.20$ to 2.28$)$ & 0.97 & 0.0 \\
\hline
\end{tabular}

Abbreviations: ESR erythrocyte sedimentation rate, $\mathrm{HCQ}$ Hydroxychloroquine, $\mathrm{Cl}$ confidence interval; wmd, weighted mean difference 
Proportion meta-analysis plot [fixed effects]

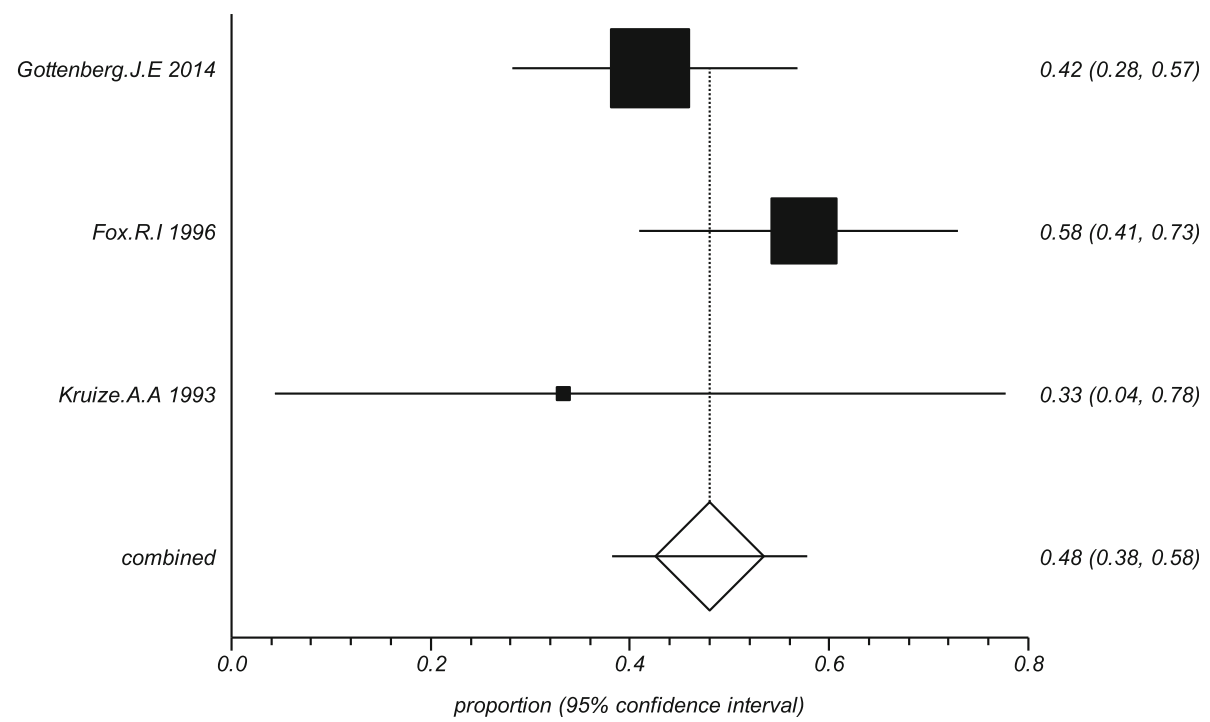

Fig. 2 The efficacy of hydroxychloroquine treatment for dry mouth in primary Sjogren's syndrome

apparent clinical benefit for dry eyes and systemic inflammation in pSS. The Sjogren's Syndrome Foundation Clinical Practice Guidelines currently recommend the use of HCQ to treat some of the symptoms of SS [41]. However, there is currently no evidence-based medical proof to support this approach. This is the first study to perform a systematic evaluation of the safety and efficacy of HCQ in the treatment of SS.

Of the four studies included in this research, three $[31,37,39]$ adopted different scales to evaluate the efficacy of HCQ in treating the subjective symptoms of pSS. As can be seen from the combined results of these three studies, the efficacy of HCQ for dry mouth was slightly higher than placebo. However, only one [39] of these was a high-quality RCT study, which showed no statistically significant difference between HCQ and placebo in relieving dryness symptoms. This RCT study [39] also measured unstimulated salivary flow rate. The results show that there was no significant difference in the amount of saliva secreted between patients treated with HCQ and placebo, which is consistent with the result of another

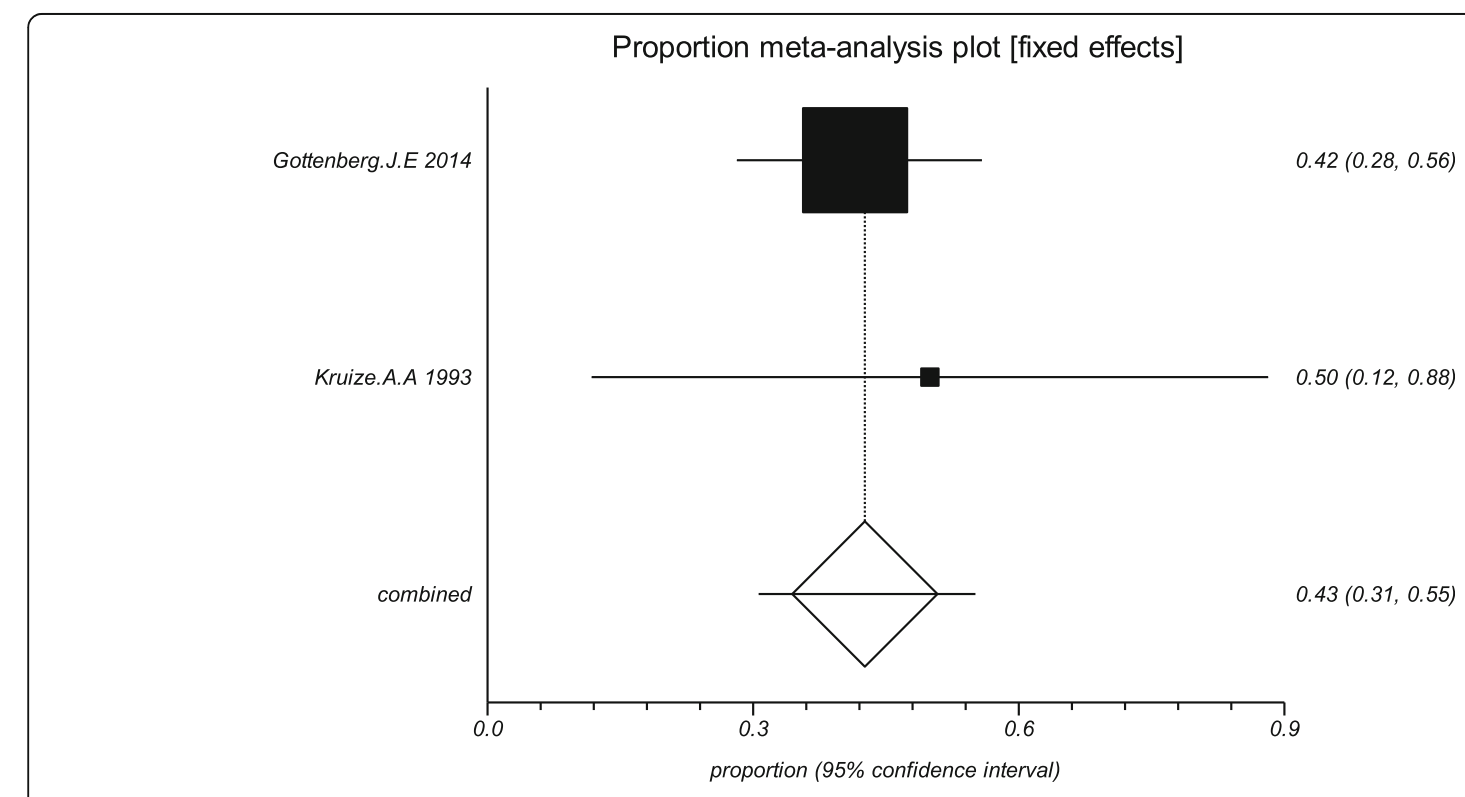

Fig. 3 The efficacy of placebo treatment for dry mouth in primary Sjogren's syndrome 
Proportion meta-analysis plot [random effects]

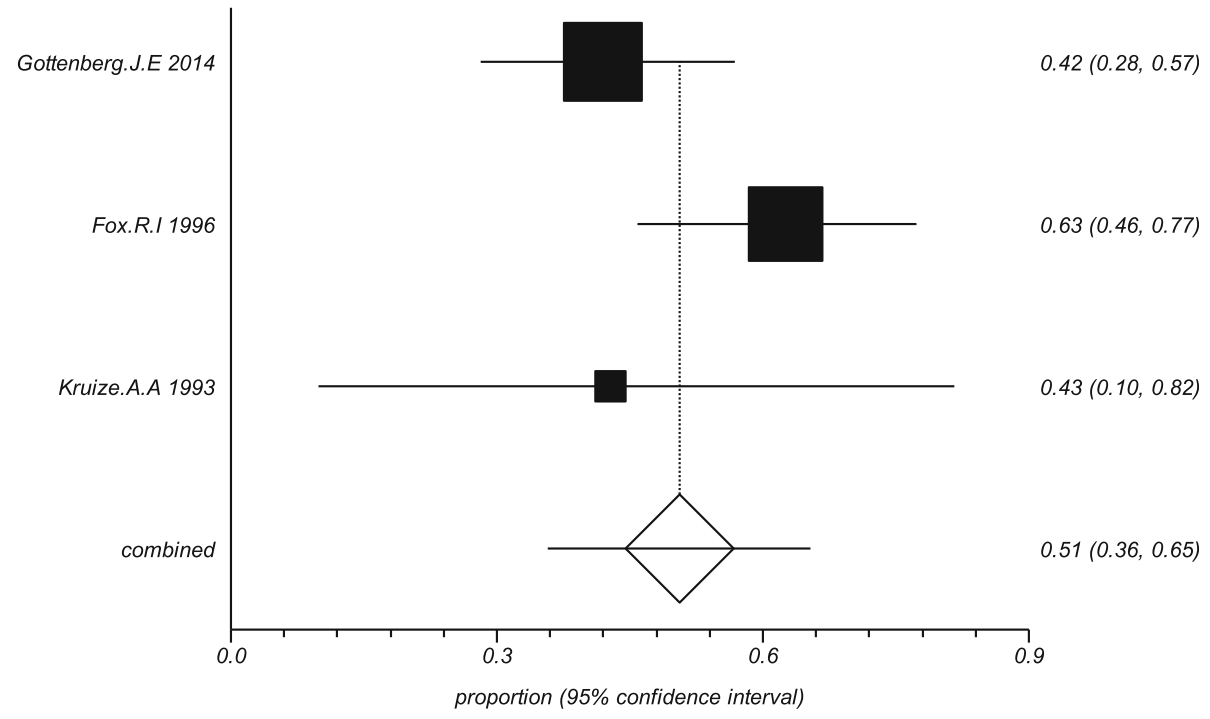

Fig. 4 The efficacy of HQ treatment for dry eyes in primary Sjogren's syndrome

case series study [38]. Similarly, in terms of dry eyes, the combined results of the three studies [31, 37, 39] show that HCQ produced a slightly higher response rate than placebo, but the only RCT study showed no statistically significant difference. In addition, one RCT study used ocular surface disease index (OSDI) to evaluate the symptoms of dry eye after HCQ treatment in patients with SS, and the results showed there were no statistically significant difference between HCQ and placebo in relieving dryness symptoms [40]. Furthermore, three [37, 39, 40] of the four studies reported Schirmer test results. Combining the results of these three studies [37, 39, 40], the Schirmer test results revealed no significant difference between the impact of HCQ and placebo. Two [39, 40] of these three studies were high-quality RCT studies, and the results of the current meta-analysis show no heterogeneity. Therefore, HCQ has extremely limited efficacy in the treatment of dry mouth and dry eyes based on the current published articles.

Three [31, 37, 39] of the four studies reported on the efficacy of $\mathrm{HCQ}$ in treating pain and fatigue. The

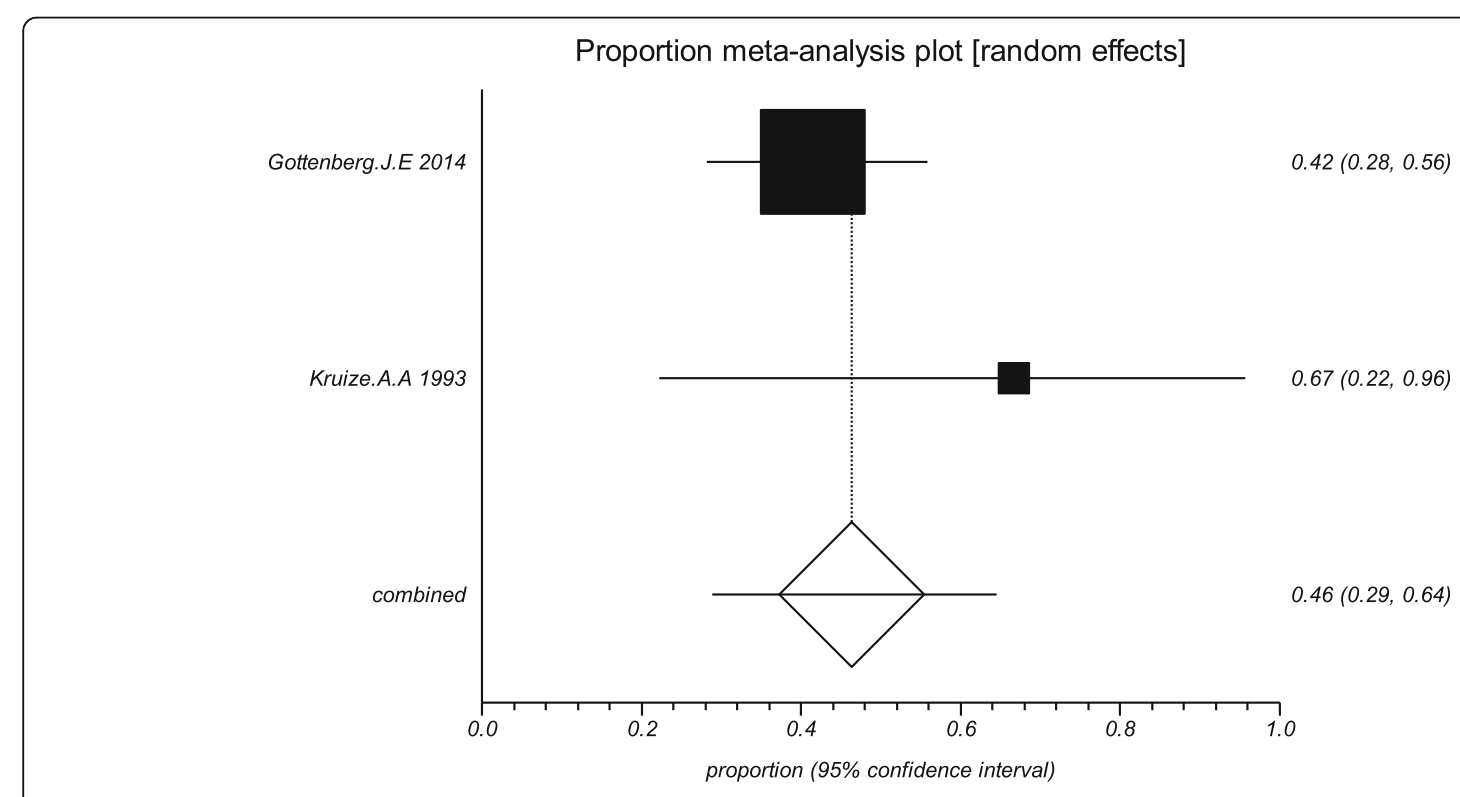

Fig. 5 The efficacy of placebo treatment for dry eyes in primary Sjogren's syndrome 
Proportion meta-analysis plot [random effects]

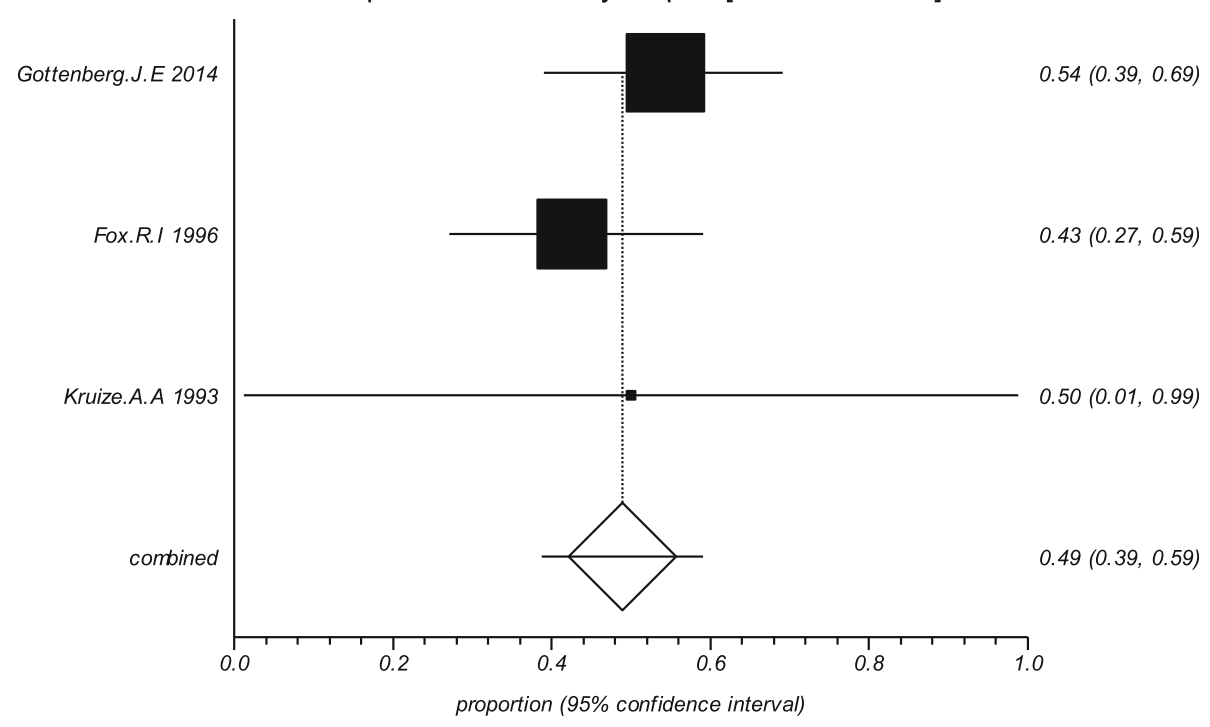

Fig. 6 The efficacy of hydroxychloroquine treatment for pain in primary Sjogren's syndrome

combined results of the studies show that HCQ was more effective in relieving pain associated with pSS than placebo; however, HCQ was somewhat less effective than placebo in relieving fatigue in pSS patients. The only RCT study [39] showed that there was no statistically significant difference between HCQ and placebo in alleviating fatigue and pain. Furthermore, three [37, 39, 40] of the four studies included in the current analysis reported the results of ESR tests. The combining results of these three studies showed that when compared with placebo group, HCQ treatment could effectively reduce ESR in patients with pSS. Therefore, it was concluded that HCQ had no effect upon pain, fatigue, but HCQ could reduce the ESR of pSS patients.

With regard to the safety of HCQ in the treatment of SS, three $[31,37,39]$ of the four studies recorded side effects or adverse events after treatment. Among the 116 patients in the HCQ group, there were nine adverse effects and two adverse events, while among the 73 patients in the placebo group, there were three adverse events but no adverse effects. Of the nine adverse effects in the HCQ group, eight occurred in patients who participated in the same study [31], among which, five patients suffered gastrointestinal issues, and three patients suffered a rash attributed to the

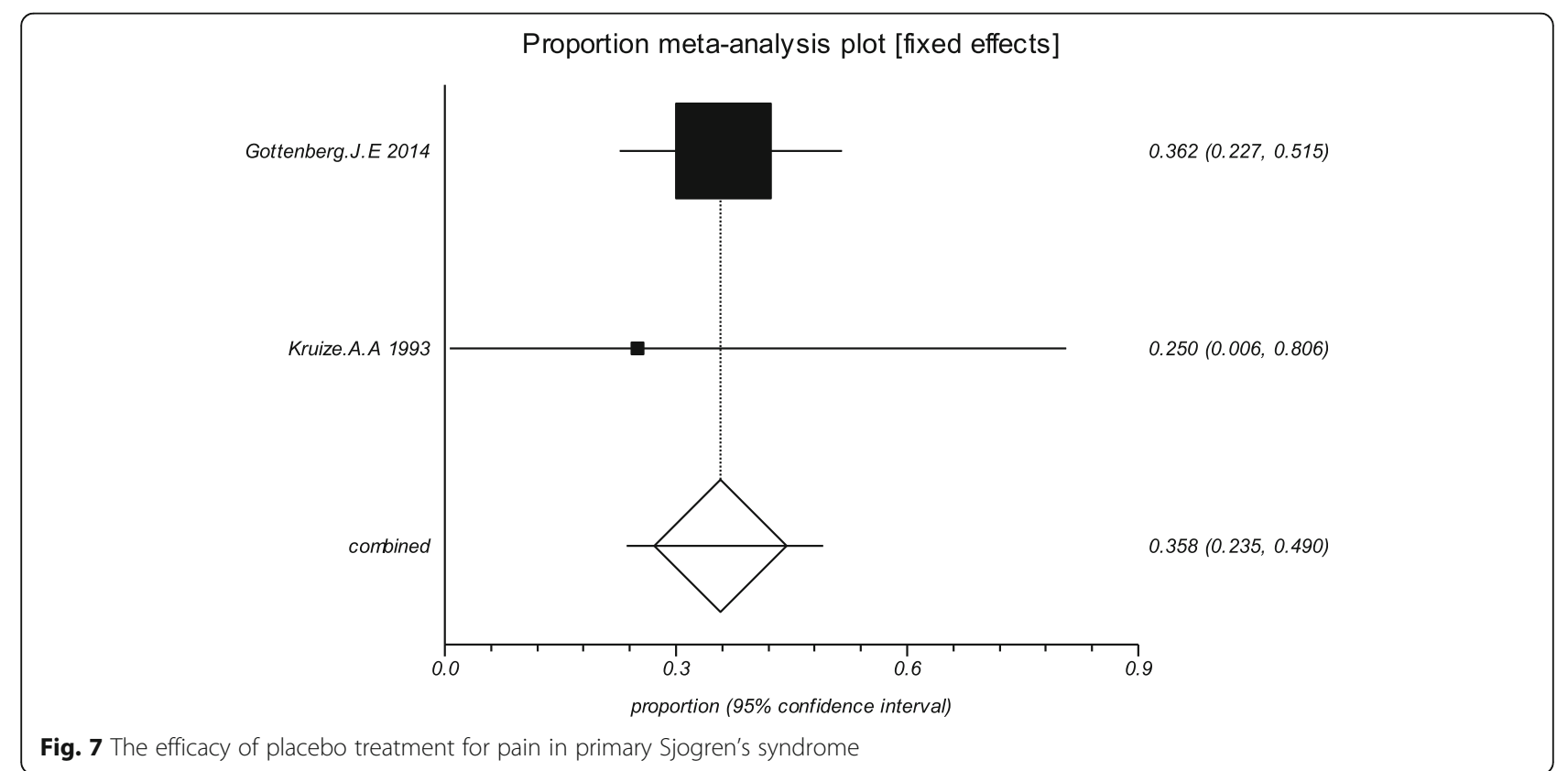


Proportion meta-analysis plot [random effects]

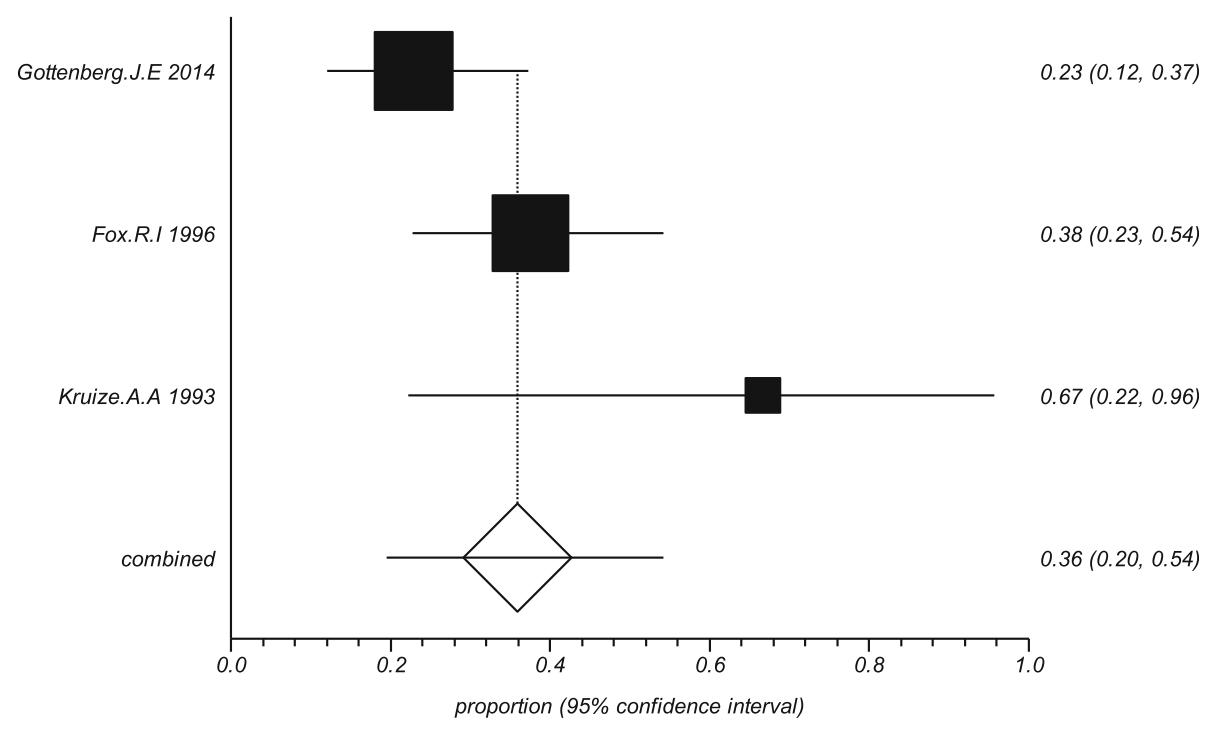

Fig. 8 The efficacy of hydroxychloroquine treatment for fatigue in primary Sjogren's syndrome

drug, and this study did not set placebo group. In the study by Kruize et al. [22], one patient demonstrated liver damage after receiving HCQ. In the study by Gottenberg et al. [24], there were two (urinary lithiasis, breast cancer) serious adverse events in the HCQ group (56 patients) and three (surgery for meningioma, lipothymia, EBV and CMV pneumonia) in the placebo group (64 patients). The occurrence of adverse events in the HCQ group (3.6\%) was not significantly different to that in the placebo group (4.7\%).
Therefore, these results suggest that HCQ is safe for use in the treatment of pSS.

Although the present study provided an objective and comprehensive evaluation of the safety and efficacy of HCQ in the treatment of pSS, there are some limitations that need to be addressed. Firstly, all the included literature was in English, and therefore literature in other languages may have been overlooked. Secondly, relatively few studies were included. A total of four studies

Proportion meta-analysis plot [random effects]

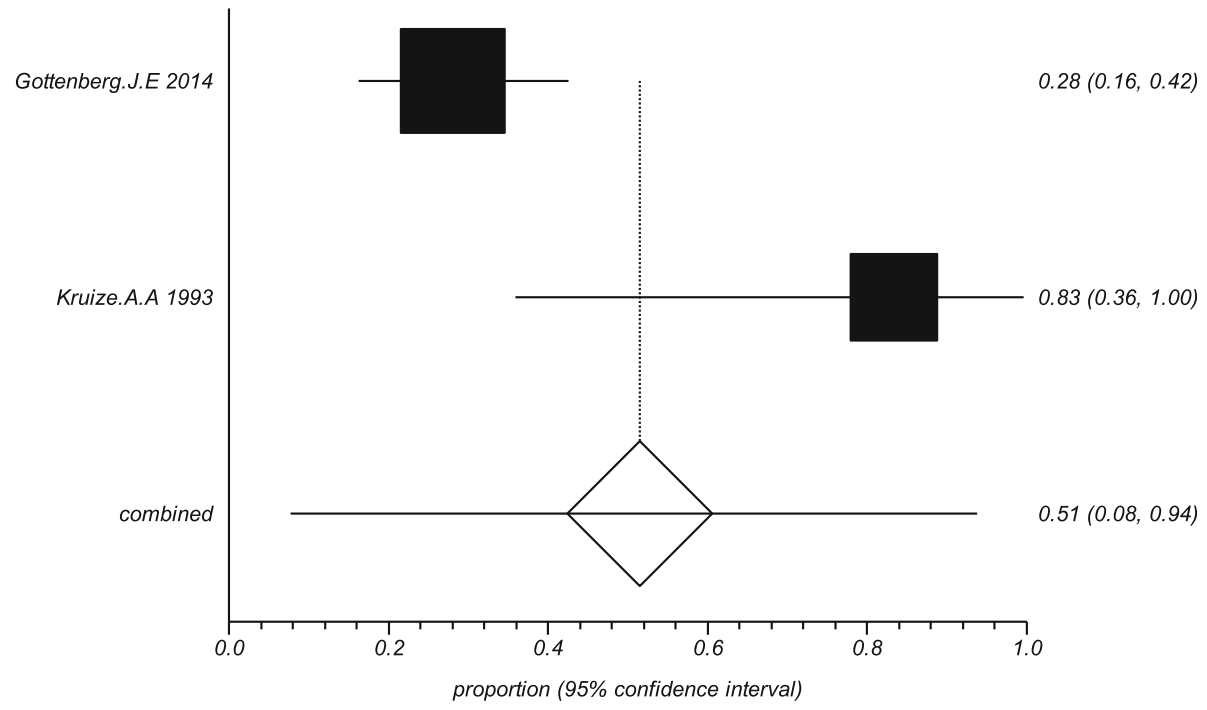

Fig. 9 The efficacy of placebo treatment for fatigue in primary Sjogren's syndrome 


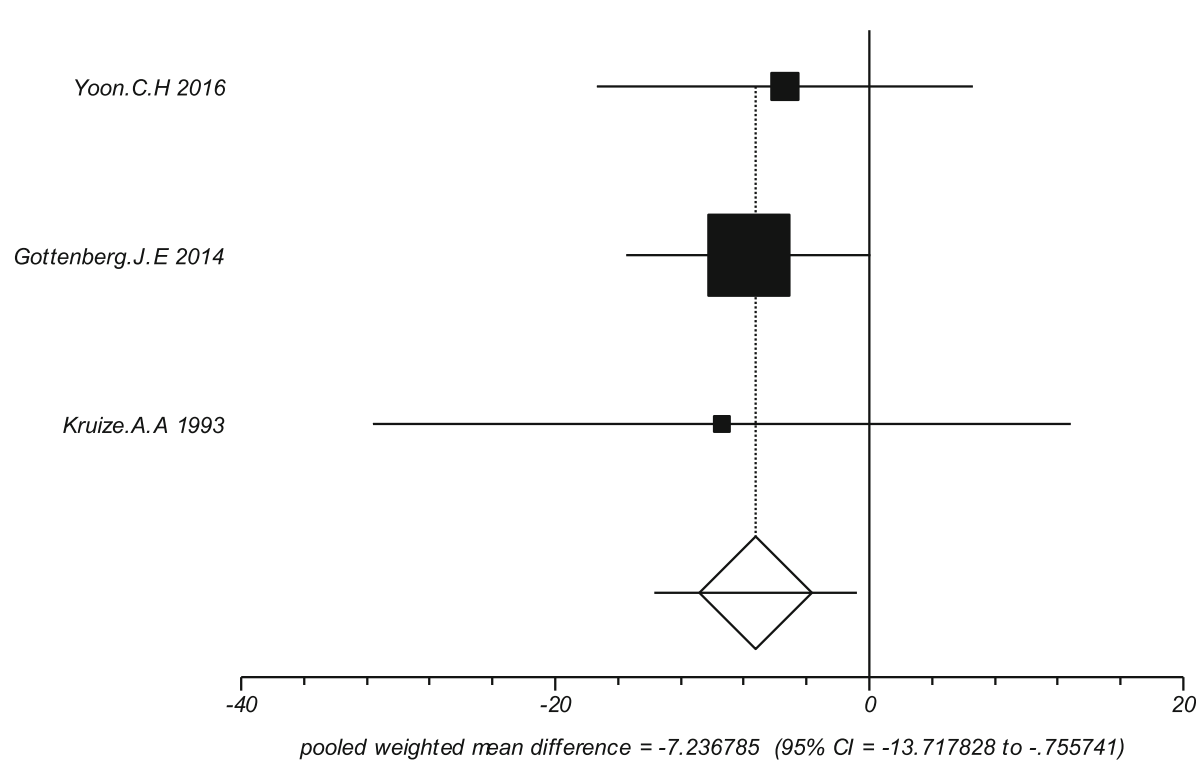

Fig. 10 The pooled weighted mean difference of hydroxychloroquine versus placebo in erythrocyte sedimentation rate

were included, of which only two were RCT studies, leading to a lower level of evidence. Thirdly, there were slight differences in the dosage and course of treatment among the four studies, which may impact prognosis to a certain extent. Fourth, subjective symptoms were evaluated and each study used a different scale for evaluation, which may also influence the results. Lastly, considering the results are largely determined by one or two researchs due to its sample size, the underlying bias should not be ignored. Based on the above limitations, a full analysis of the objective effects of HCQ in the treatment of pSS should be performed and the clinical role of HCQ should not be expanded. Future high-quality RCTs with large populations are essential to confirm the efficacy of HCQ for treating pSS.

\section{Conclusion}

In summary, the efficacy of HCQ to alleviate the sicca manifestations of pSS, based on current published studies, is extremely limited. Considering the wide use of HCQ in

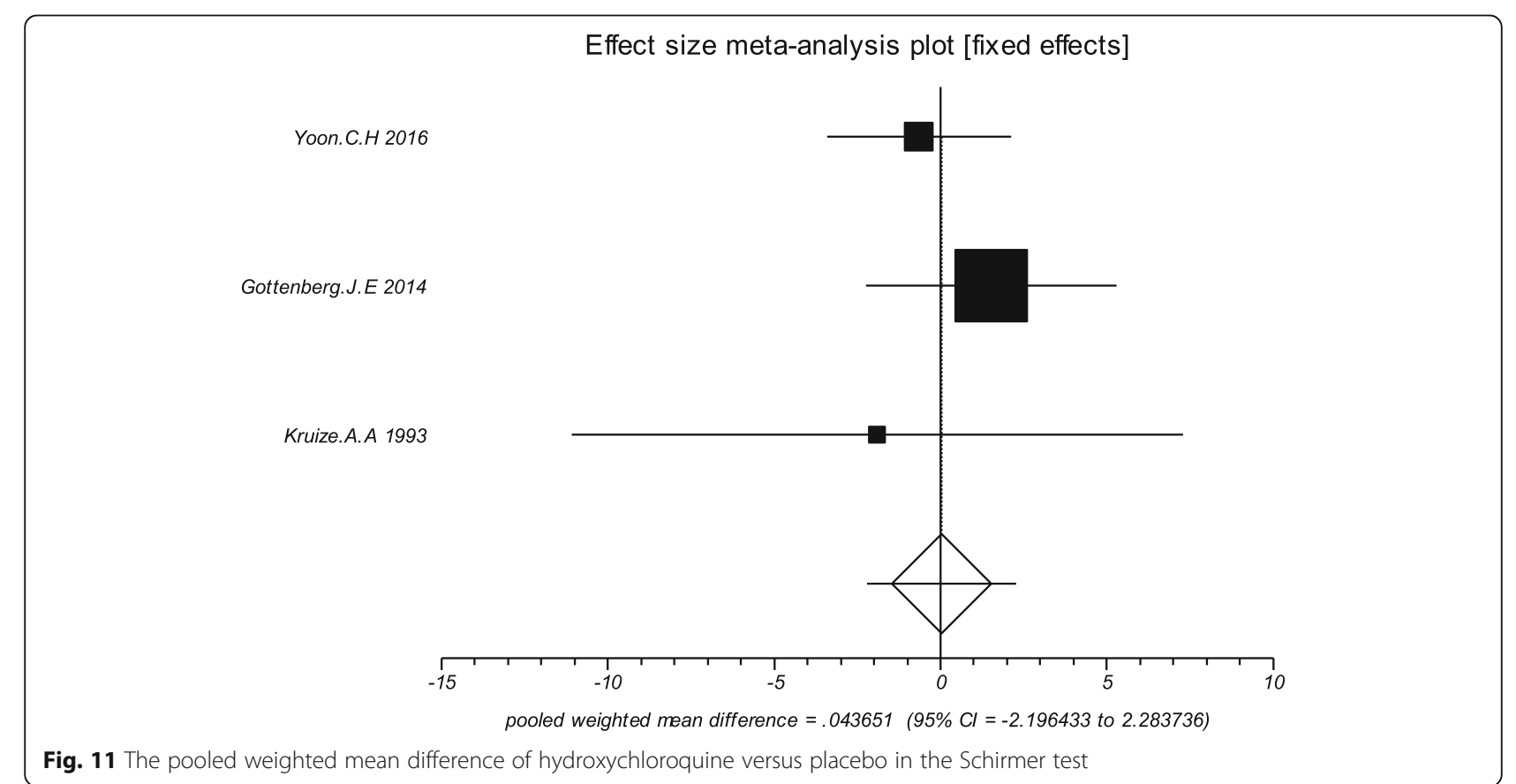


treating pSS, well-designed, randomized, controlled trials are needed to provide higher-quality evidence to confirm our findings, and future studies should focus on other outcome measures, such as cutaneous manifestations et al, to objectively and comprehensively explore the role of HCQ in the treatment of pSS.

\section{Additional file}

Additional file 1: An additional file shows the characteristics of the included studies. (DOC $33 \mathrm{~kb}$ )

\section{Abbreviations}

BAFF: B-cell activator factor; Cl: Confidence interval; CMV: Cytomegalovirus; EBV: Epstein-Barr virus; EMBASE: Excerpta Medica Database ; ESR: Erythrocyte sedimentation rate; HCQ: Hydroxychloroquine; OCEBM: Oxford centre for evidence-based medicine; pSS: Primary Sjogren's syndrome; RA: Rheumatoid arthritis; RCTs: Randomized controlled trials; SLE: Systemic lupus erythematosus; SS: Sjogren's syndrome; sSS: Secondary Sjogren's syndrome; wmd: Weighted mean difference

\section{Acknowledgements}

We thank Dr. Shang Xie, Peking University School and Hospital of Stomatology, for the careful review of the final manuscript and editing and checking the accuracy of numbers compared to results of the analyses. We would like to thank the native English speaking scientists of Elixigen Company (Huntington Beach, California) for editing our manuscript.

\section{Funding}

This work was supported by the National Natural Science Foundation of China [grant number 81371163].

\section{Availability of data and materials}

Not applicable.

\section{Authors' contributions}

Shi-Qin Wang and Li-Wei Zhang participated in data acquisition, analysis and interpretation. Shi-Qin Wang drafted the manuscript. Hong Hua and Pan Wei participated in conception and design, critically revised the manuscript. All authors have given final approval and agree to be accountable for all aspects of the work.

\section{Competing interests}

The authors declare that they have no competing interests.

\section{Consent for publication}

Not applicable.

\section{Ethical approval and consent to participate}

This research did not involve any ethical and informed consent.

\section{Publisher's Note}

Springer Nature remains neutral with regard to jurisdictional claims in published maps and institutional affiliations.

Received: 1 December 2016 Accepted: 28 April 2017

Published online: 12 May 2017

\section{References}

1. Greenspan JS, Daniels TE, Talal N, Sylvester RA. The histopathology of Sjogren's syndrome in labial salivary gland biopsies. Oral Surg Oral Med Oral Pathol. 1974:37(2):217-29.

2. Fox PC. Autoimmune diseases and Sjogren's syndrome: an autoimmune exocrinopathy. Ann N Y Acad Sci. 2007;1098:15-21.

3. Espitia-Thibault A, Masseau A, Neel A, Espitia O, Toquet C, Mussini JM, Hamidou M. Sjogren's syndrome-associated myositis with germinal centrelike structures. Autoimmun Rev. 2017;16(2):154-8.
4. Bolstad Al, Skarstein K. Epidemiology of Sjogren's Syndrome-from an Oral Perspective. Curr Oral Health Rep. 2016;3(4):328-36.

5. ter Borg EJ, Risselada AP, Kelder JC. Relation of systemic autoantibodies to the number of extraglandular manifestations in primary Sjogren's Syndrome: a retrospective analysis of 65 patients in the Netherlands. Semin Arthritis Rheum. 2011:40(6):547-51.

6. Baldini C, Pepe P, Quartuccio L, Priori R, Bartoloni E, Alunno A, Gattamelata A, Maset M, Modesti M, Tavoni A, et al. Primary Sjogren's syndrome as a multi-organ disease: impact of the serological profile on the clinical presentation of the disease in a large cohort of Italian patients. Rheumatology (Oxford, England). 2014;53(5):839-44.

7. Ramos-Casals M, Brito-Zeron P, Seror R, Bootsma H, Bowman SJ, Dorner T, Gottenberg JE, Mariette X, Theander E, Bombardieri S, et al. Characterization of systemic disease in primary Sjogren's syndrome: EULAR-SS Task Force recommendations for articular, cutaneous, pulmonary and renal involvements. Rheumatology (Oxford, England). 2015;54(12):2230-8.

8. Fox RI. Sjogren's syndrome. Lancet (London, England). 2005;366(9482):321-31.

9. Drosos AA, Andonopoulos AP, Costopoulos JS, Papadimitriou CS, Moutsopoulos HM. Prevalence of primary Sjogren's syndrome in an elderly population. Br J Rheumatol. 1988;27(2):123-7.

10. Venables PJ. Sjogren's syndrome. Best Pract Res Clin Rheumatol. 2004;18(3): $313-29$.

11. Chiorini JA, Cihakova D, Ouellette CE, Caturegli P. Sjogren syndrome: advances in the pathogenesis from animal models. J Autoimmun. 2009; 33(3-4):190-6

12. Qin B, Wang J, Yang Z, Yang M, Ma N, Huang F, Zhong R. Epidemiology of primary Sjogren's syndrome: a systematic review and meta-analysis. Ann Rheum Dis. 2015;74(11):1983-9.

13. Goules AV, Tzioufas AG. Primary Sjgren's syndrome: Clinical phenotypes, outcome and the development of biomarkers. Autoimmun Rev. 2016;15(7):695-703.

14. Liang Y, Yang Z, Qin B, Zhong R. Primary Sjogren's syndrome and malignancy risk: a systematic review and meta-analysis. Ann Rheum Dis. 2014;73(6):1151-6.

15. Bostrom EA, d'Elia HF, Dahlgren U, Simark-Mattsson C, Hasseus B, Carlsten H, Tarkowski A, Bokarewa M. Salivary resistin reflects local inflammation in Sjogren's syndrome. J Rheumatol. 2008;35(10):2005-11.

16. Forsblad-d'Elia H, Carlsten H, Labrie F, Konttinen YT, Ohlsson C. Low serum levels of sex steroids are associated with disease characteristics in primary Sjogren's syndrome; supplementation with dehydroepiandrosterone restores the concentrations. J Clin Endocrinol Metab. 2009;94(6):2044-51.

17. Nikolov NP, Illei GG. Pathogenesis of Sjogren's syndrome. Curr Opin Rheumatol. 2009;21(5):465-70.

18. Roescher N, Tak PP, Illei GG. Cytokines in Sjogren's syndrome: potential therapeutic targets. Ann Rheum Dis. 2010;69(6):945-8.

19. Alunno A, Carubbi F, Bartoloni E, Bistoni O, Caterbi S, Cipriani P, Giacomelli R, Gerli R. Unmasking the pathogenic role of IL-17 axis in primary Sjogren's syndrome: a new era for therapeutic targeting? Autoimmun Rev. 2014; 13(12):1167-73.

20. Mackay F, Groom JR, Tangye SG. An important role for B-cell activation factor and B cells in the pathogenesis of Sjogren's syndrome. Curr Opin Rheumatol. 2007:19(5):406-13.

21. Verstappen GM, Kroese FG, Meiners PM, Corneth OB, Huitema MG, Haacke EA, van der Vegt B, Arends S, Vissink A, Bootsma H, et al. B Cell Depletion Therapy Normalizes Circulating Follicular Th Cells in Primary Sjogren Syndrome. J Rheumatol. 2017:44(1):49-58.

22. Carsons SE, Vivino FB, Parke A, Carteron N, Sankar V, Brasington R, Brennan MT, Ehlers W, Fox R, Scofield $H$ et al. Treatment Guidelines for Rheumatologic Manifestations of Sjogren's: Use of Biologics, Management of Fatigue and Inflammatory Musculoskeletal Pain. Arthritis Care Res. 2017; 69(4):517-27.

23. Ramos-Casals M, Tzioufas AG, Stone JH, Siso A, Bosch X. Treatment of primary Sjogren syndrome: a systematic review. Jama. 2010;304(4):452-60.

24. Valim V, Trevisani VF, Pasoto SG, Serrano EV, Ribeiro SL, Fidelix TS, Vilela VS, Prado LL, Tanure LA, Liborio-Kimura TN, et al. Recommendations for the treatment of Sjogren's syndrome. Rev Bras Reumatol. 2015;55(5):446-57.

25. Cornec D, Jamin C, Pers JO. Sjogren's syndrome: where do we stand, and where shall we go? J Autoimmun. 2014;51:109-14.

26. Saraux A, Pers JO, Devauchelle-Pensec V. Treatment of primary Sjogren syndrome. Nat Rev Rheumatol. 2016;12(8):456-71.

27. Goodman SM. Rheumatoid arthritis: Perioperative management of biologics and DMARDs. Semin Arthritis Rheum. 2015;44(6):627-32. 
28. Rainsford KD, Parke AL, Clifford-Rashotte M, Kean WF. Therapy and pharmacological properties of hydroxychloroquine and chloroquine in treatment of systemic lupus erythematosus, rheumatoid arthritis and related diseases. Inflammopharmacology. 2015;23(5):231-69.

29. Ruiz-Irastorza G, Ramos-Casals M, Brito-Zeron P, Khamashta MA. Clinical efficacy and side effects of antimalarials in systemic lupus erythematosus: a systematic review. Ann Rheum Dis. 2010;69(1):20-8.

30. Suarez-Almazor ME, Belseck E, Shea B, Homik J, Wells G, Tugwell P. Antimalarials for rheumatoid arthritis. Cochrane Database of Syst Revi. 2000; (2):Cd000959.

31. Fox Rl, Dixon R, Guarrasi V, Krubel S. Treatment of primary Sjogren's syndrome with hydroxychloroquine: a retrospective, open-label study. Lupus. 1996;5 Suppl 1:S31-6.

32. Tishler M, Yaron I, Shirazi I, Yaron M. Hydroxychloroquine treatment for primary Sjogren's syndrome: its effect on salivary and serum inflammatory markers. Ann Rheum Dis. 1999;58(4):253-6.

33. Mumcu G, Bicakcigil M, Yilmaz N, Ozay H, Karacayli U, Cimilli H, Yavuz S. Salivary and serum B-cell activating factor (BAFF) levels after hydroxychloroquine treatment in primary Sjogren's syndrome. Oral Health Prev Dent. 2013;11(3):229-34.

34. Ramos-Casals M, Brito-Zeron P, Siso-Almirall A, Bosch X. Primary Sjogren syndrome. BMJ (Clin Res Ed). 2012;344:e3821.

35. Ramos-Casals M, Brito-Zeron P, Siso-Almirall A, Bosch X, Tzioufas AG. Topical and systemic medications for the treatment of primary Sjogren's syndrome. Nat Rev Rheumatol. 2012;8(7):399-411.

36. Gottenberg JE, Seror R, Miceli-Richard C, Benessiano J, Devauchelle-Pensec V, Dieude P, Dubost JJ, Fauchais AL, Goeb V, Hachulla E, et al. Serum levels of beta2-microglobulin and free light chains of immunoglobulins are associated with systemic disease activity in primary Sjogren's syndrome. Data at enrollment in the prospective ASSESS cohort. PLoS One. 2013;8(5):e59868.

37. Kruize AA, Hene RJ, Kallenberg CG, van Bijsterveld OP, van der Heide A, Kater L, Bijlsma JW. Hydroxychloroquine treatment for primary Sjogren's syndrome: a two year double blind crossover trial. Ann Rheum Dis. 1993;52(5):360-4.

38. Cankaya H, Alpoz E, Karabulut G, Guneri P, Boyacioglu H, Kabasakal Y. Effects of hydroxychloroquine on salivary flow rates and oral complaints of Sjogren patients: a prospective sample study. Oral Surg Oral Med Oral Pathol Oral Radiol Endod. 2010;110(1):62-7.

39. Gottenberg JE, Ravaud P, Puechal X, Le Guern V, Sibilia J, Goeb V, Larroche C, Dubost JJ, Rist S, Saraux A, et al. Effects of hydroxychloroquine on symptomatic improvement in primary Sjogren syndrome: the JOQUER randomized clinical trial. Jama. 2014;312(3):249-58.

40. Yoon $\mathrm{CH}$, Lee HJ. Effect of Hydroxychloroquine Treatment on Dry Eyes in Subjects with Primary Sjogren's Syndrome: a Double-Blind Randomized Control Study. J Korean Med Sci. 2016:31(7):1127-35.

41. Vivino FB, Carsons SE, Foulks G, Daniels TE, Parke A, Brennan MT, Forstot SL, Scofield RH, Hammitt KM. New Treatment Guidelines for Sjogren's Disease. Rheum Dis Clin N Am. 2016;42(3):531-51.

42. Shamseer L, Moher D, Clarke M, Ghersi D, Liberati A, Petticrew M, Shekelle P, Stewart LA. Preferred reporting items for systematic review and meta-analysis protocols (PRISMA-P) 2015: elaboration and explanation. BMJ (Clin Res Ed). 2015;349:g7647.

43. Downs SH, Black N. The feasibility of creating a checklist for the assessment of the methodological quality both of randomised and non-randomised studies of health care interventions. J Epidemiol Community Health. 1998;52(6):377-84.

44. DerSimonian R, Laird N. Meta-analysis in clinical trials. Control Clin Trials. 1986;7(3):177-88.

45. loannidis JP. Interpretation of tests of heterogeneity and bias in metaanalysis. J Eval Clin Pract. 2008;14(5):951-7.

46. Heaton JM. The treatment of Sjogren's syndrome with hydroxychloroquine. Am J Ophthalmol. 1963;55:982-6.

47. Senecal JL, Chartier $\mathrm{S}$, Rothfield N. Hypergammaglobulinemic purpura in systemic autoimmune rheumatic diseases: predictive value of anti-Ro(SSA) and anti-La(SSB) antibodies and treatment with indomethacin and hydroxychloroquine. J Rheumatol. 1995;22(5):868-75.

48. Fox R. Anti-malarial drugs: possible mechanisms of action in autoimmune disease and prospects for drug development. Lupus. 1996:5 Suppl 1:S4-S10.

49. Pillemer SR, Pando J, Magno B, Kurrasch R, Atkinson J, Macynski A, Fox P. Hydroxychloroquine for Sjogren's syndrome: A double-blind placebo controlled pilot trial. Arthritis Rheum. 1997:40(9 SUPPL):S203.

50. Oxholm P, Prause JU, Schiodt M. Rational drug therapy - Recommendations for the treatment of patients with Sjogren's syndrome. Drugs. 1998:56(3):345-53.
51. Fox RI, Chan E, Benton L, Fong S, Friedlaender M, Howell FV. Treatment of primary Sjogren's syndrome with hydroxychloroquine. Am J Med. 1988; 85(4a):62-7.

52. Yavuz S, Asfuroglu E, Bicakcigil M, Toker E. Hydroxychloroquine improves dry eye symptoms of patients with primary Sjogren's syndrome. Rheumatol Int. 2011;31(8):1045-9.

\section{Submit your next manuscript to BioMed Central and we will help you at every step:}

- We accept pre-submission inquiries

- Our selector tool helps you to find the most relevant journal

- We provide round the clock customer support

- Convenient online submission

- Thorough peer review

- Inclusion in PubMed and all major indexing services

- Maximum visibility for your research

Submit your manuscript at www.biomedcentral.com/submit
Biomed Central 